\section{BMJ Open Respiratory Research}

\title{
Venous thromboembolism in patients with COVID-19 and correlation with D- dimers: a single-centre experience
}

\author{
Muhammad Ziaullah Khan (D) , Yousaf Jamal, Benjamin Sutton, Farrukh Rauf
}

To cite: Khan MZ, Jamal Y, Sutton B, et al. Venous thromboembolism in patients with COVID-19 and correlation with D-dimers: a single-centre experience. BMJ Open Resp Res 2020;7:e000779. doi:10.1136/ bmjresp-2020-000779

Received 18 September 2020 Revised 23 October 2020 Accepted 28 October 2020

\section{Check for updates}

(c) Author(s) (or their employer(s)) 2020. Re-use permitted under CC BY-NC. No commercial re-use. See rights and permissions. Published by BMJ.

Department of Respiratory Medicine, Queen Elizabeth Hospital, University Hospitals Birmingham NHS Foundation Trust, Birmingham, United Kingdom

Correspondence to Dr Muhammad Ziaullah Khan; ziaullah.khan@nhs.net

\section{ABSTRACT}

Objective To study the frequency of venous

thromboembolism in hospitalised patients with COVID-19

and correlation with the D-dimers and thromboprophylaxis.

Design Cross-sectional descriptive study.

Place and duration of study Queen Elizabeth Hospital, 20 April 2020-13 May 2020.

Patients and methods One hundred and seven $(n=107)$ patients of PCR-confirmed COVID-19 pneumonia admitted to Queen Elizabeth Hospital, Birmingham, between 20 Apri 2020 and 13 May 2020 were included in the study using consecutive sampling. Data were collected using the Excel audit tool and included age, gender, weight, estimated eGFR, D-dimer values on admission, intensive care unit admission, presence of respiratory failure, imaging results for evaluation of venous thromboembolism (VTE) and anticoagulation received on admission. The data were entered in the SPSS (V.17) and were analysed. Data were summarised as means $\pm \mathrm{SD}$, number or percentage as appropriate. A p value of less than 0.05 was considered significant.

Results The frequency of VTE was found to be $11.2 \%$ in patients hospitalised with COVID-19 pneumonia. The mean D-dimers were $3322.24 \mathrm{ng} / \mathrm{mL} \pm 9603 \mathrm{ng} / \mathrm{mL}$ with the values significantly higher for patients with VTE and those requiring intensive care unit admission. All of the seven patients (100\%) with D-dimers value above $2000 \mathrm{ng} / \mathrm{mL}$ who underwent imaging were found to have VTE.

Conclusion VTE is frequent in patients with COVID-19 pneumonia despite anticoagulation. A higher D-dimers value correlates well with the risk of VTE in these patients and further evaluation of such patients for VTE is necessary especially with D-dimers values above $2000 \mathrm{ng} / \mathrm{mL}$.

\section{OBJECTIVES}

To study the frequency of venous thromboembolism in hospitalised patients with COVID-19 and correlation with the D-dimers and thromboprophylaxis.

\section{INTRODUCTION}

COVID-19 is a new highly contagious viral illness caused by novel coronavirus (SARS-CoV-2) that emerged in Wuhan City in China in December 2019. ${ }^{1}$ Since then, it has spread across the globe, and the outbreak

\section{Key messages \\ What is the key question? \\ - To assess the incidence of venous thromboembo- lism (VTE) in patients with COVID-19 infection and clinically significant cut-off D-dimer values in these cases to suggest likelihood of VTE or otherwise. \\ What is the bottom line? \\ - There is a VTE incidence of about 11\% in COVID-19 infection despite adequate prophylactic anticoagu- lation and a D-dimer value above $2000 \mathrm{ng} / \mathrm{mL}$ cor- relates well with a radiological confirmation of VTE; therefore, the authors recommend appropriate im- aging to exclude VTE if the D-dimers are more than $2000 \mathrm{ng} / \mathrm{mL}$. \\ Why read on? \\ - The study further informs the readers of the real time National Health Service hospital evidence of coagu- lopathy in patients with COVID-19 and also helps in establishing a cut-off value for D-dimers, which will help in establishing an appropriate diagnostic algo- rithm for VTE in similar cases and their subsequent management.}

was declared as a Public Health Emergency of International Concern in January 2020.

Most cases are asymptomatic or have mild symptoms including fever, malaise, fatigue, body aches, anosmia and cough. However, in severe illness and particularly those with cytokine storm syndrome, patients can rapidly develop acute respiratory distress syndrome, septic shock, renal failure, hepatitis and coagulopathy including venous thromboembolism (VTE) and disseminated intravascular coagulation. $^{2}$

Patients with severe and critical COVID-19 illness are at increased risk of VTE due to multiple factors including immobilisation, infection, respiratory failure, mechanical ventilation and central venous catheters. Coagulopathy and high D-dimer values have been reported in many studies in these patients with COVID-19, and this phenomenon is associated with increased mortality. ${ }^{34}$ 
High D-dimer values are often overlooked and considered insignificant being a usual finding in patients with COVID-19. In this cross-sectional study, we evaluated the hospitalised patients with COVID-19 infection for the frequency of VTE and correlated their D-dimers values and anticoagulation status with the risk of thromboembolism.

\section{METHODOLOGY}

This retrospective cross-sectional study was performed at Queen Elizabeth Hospital, University Hospital Birmingham. Inclusion criteria included adult patients hospitalised with positive swab PCR-detected SARS-CoV2 during the period from 20 April 2020 to 13 May 2020.

A total of 107 patients admitted in this period were included in the study by consecutive non-probability sampling. Data were collected through our inpatient management system Prescribing Information \& Communication System using an Excel audit tool. The parameters included age, gender, weight, eGFR (estimated glomerular filtration rate), D-dimer values and anticoagulation status on admission, need for intensive care unit (ICU) admission, presence or absence of respiratory failure and VTE during the course of admission.

Patients were classified as receiving optimal, suboptimal or therapeutic anticoagulation by assessing the regimen against the trust guidelines as per following definition:

1. Optimal anticoagulation: patients weighing $<99 \mathrm{~kg}$ on enoxaparin $40 \mathrm{mg}$ daily. If weighing $100-150 \mathrm{~kg}$, then enoxaparin $40 \mathrm{mg}$ twice daily and with weight $100-150 \mathrm{~kg}$ enoxaparin $60 \mathrm{mg}$ twice daily in all care settings. Critical care patients with weight $<100 \mathrm{~kg}$ should have enoxaparin $40 \mathrm{mg}$ twice daily. If eGFR $<30 \mathrm{~mL} /$ min, then reduce dose by $50 \%$, and if having continuous veno-venous hemodiafiltration on critical care, then $40 \mathrm{mg}$ once daily.

2. Suboptimal anticoagulation: patients receiving less than optimal dose adjusted for weight and eGFR.

3. Therapeutic anticoagulation: patient started acutely on enoxaparin $1.5 \mathrm{mg} / \mathrm{kg}$ with confirmed/suspicion of VTE.

4. Patient already on direct oral anticoagulants (DOACS)/warfarin for known atrial fibrillation/previous VTE.

The data was entered in SPSS (V.17) and analysed. Data was summarised as means $\pm \mathrm{SD}$, number or percentage as appropriate. Fisher's exact test and t-test were used for the comparison of variables and data as applicable. A p value of less than 0.05 was considered significant.

There was no involvement of the patients or public in the design, conduct, reporting or dissemination plans of our observational study, as it was not required.

\section{RESULTS}

A total number of 107 patients, 62 men $(57.9 \%)$ and 45 women $(42.1 \%)$ were evaluated during the duration of the study. The mean age of the patients was $68.9 \pm 17.847$ years. Ninety-seven patients $(90.7 \%)$ had respiratory failure, while 37 patients $(34.6 \%)$ required admission to the ICU (tables 1 and 2).

A total of 72 patients $(67.3 \%)$ had D-dimers done during the course of their admission, and only 54 patients $(50.5 \%)$ had D-dimers done within the first 24 hours (table 2). The mean D-dimer value was $3322.24 \mathrm{ng} /$ $\mathrm{mL} \pm 9603 \mathrm{ng} / \mathrm{mL}$ with a maximum of $72467 \mathrm{ng} / \mathrm{mL}$ (table 1). The mean $\mathrm{D}$-dimer value was significantly higher for patients requiring ICU admission. Similarly, values were higher for patients with respiratory failure but did not reach statistical significance (table 3).

Twenty-three patients $(21.5 \%)$ underwent imaging including CT pulmonary angiogram (CTPA) (13 patients) and Doppler ultrasound (10 patients) for further evaluation of VTE (table 2). Overall, 12 patients $(11.2 \%)$ were found to have VTE on dedicated imaging, 6 patients had PE (50\%) while 6 patients had DVT $(50 \%)$ as shown in table 2 . The mean D-dimer value of the patients with confirmed VTE was significantly higher than for patients with no VTE on imaging $(16218.56 \pm 23782 \mathrm{ng} / \mathrm{mL}$, vs $808.78 \pm 466.55 \mathrm{ng} / \mathrm{mL} \mathrm{p}$ value 0.005 ) (table 3 ).

All seven patients $(100 \%)$ with D-dimers greater than $2000 \mathrm{ng} / \mathrm{mL}$ evaluated with dedicated imaging were positive for VTE, while only two $(n=11,18.18 \%)$ patients with D-dimers less than 2000 were positive for VTE on Doppler/CTPA (table 4).

As shown in table 2, overall 104 patients (97.2 \%) received any kind of anticoagulation during their admission with $71 \%$ receiving optimal anticoagulation. Three patients did not receive anticoagulation because of contraindications including subdural haemorrhage/ thrombocytopaenia. Five patients $(4.7 \%)$ were started on therapeutic anticoagulation on admission that was continued in four of them with subsequent VTE confirmed on imaging. Nine patients $(8.4 \%)$ were

\begin{tabular}{lrrrrr}
\hline Table 1 & Age, D-dimers and days to diagnosis of VTE & \multicolumn{1}{c}{} \\
\hline \multicolumn{1}{l}{$\mathbf{N}$} & Minimum & Maximum & Mean & SD \\
\hline Age (years) & 107 & 21 & 96 & 68.96 & 17.847 \\
Initial D-dimers value $(\mathrm{ng} / \mathrm{mL})$ & 72 & 107 & 72467 & 3322.24 & 9603.921 \\
Days to diagnosis of VTE & 12 & 1 & 38 & 9.75 & 10.788 \\
\hline
\end{tabular}

VTE, venous thromboembolism. 
Table 2 Frequency of patient characteristics

\begin{tabular}{llrr}
\hline & & Frequency & Per cent \\
\hline Gender & Male & 62 & 57.9 \\
Anticoagulation protocol on admission & Female & 45 & 42.1 \\
& No anticoagulation & 3 & 2.8 \\
& Suboptimal prophylactic & 9 & 8.4 \\
& Optimal prophylactic & 76 & 71.0 \\
Type of VTE & Therapeutic dose & 5 & 4.7 \\
& On regular DOACs/warfarin & 14 & 13.1 \\
Imaging for VTE & Pulmonary embolism & 6.6 \\
& DVT & 5.6 \\
Respiratory failure & No imaging & 64.5 \\
Intensive care admission & Doppler ultrasound & 10 & 9.3 \\
& CTPA & 13 & 12.1 \\
\hline D-dimer protocol & No respiratory failure & 10 & 9.3 \\
& Respiratory failure & 97 & 90.7 \\
\hline
\end{tabular}

CTPA, CT pulmonary angiogram; DOACs, direct oral anticoagulants; DVT, deep vein thrombosis; ICU, intensive care unit; VTE, venous thromboembolism.

considered to be suboptimally anticoagulated based on their weight and eGFR. Fourteen patients (13.1\%) remained on DOACs/oral Warfarin as per their preadmission regimen.

Four patients were diagnosed with VTE on admission and placed on therapeutic anticoagulation on admission. The remaining eight patients were diagnosed to have VTE during the course of the admission despite being on optimal anticoagulation. The mean time to diagnosis of VTE was $9.50 \pm 11$ days. None of the 13 patients on DOACs/warfarin preadmission were

Table 3 Mean D-dimers value based on presence or absence of VTE, respiratory failure and ICU admission

\begin{tabular}{|c|c|c|c|c|}
\hline & $\mathbf{N}$ & Mean & SD & $P$ value \\
\hline VTE on imaging & 9 & 16218.56 & 23782.665 & 0.005 \\
\hline $\begin{array}{l}\text { No VTE on } \\
\text { imaging }\end{array}$ & 9 & 808.78 & 466.552 & \\
\hline $\begin{array}{l}\text { Respiratory } \\
\text { failure }\end{array}$ & 70 & 3401.99 & 9730.096 & 0.538 \\
\hline $\begin{array}{l}\text { No respiratory } \\
\text { failure }\end{array}$ & 2 & 531.00 & 347.897 & \\
\hline $\begin{array}{l}\text { No ICU } \\
\text { admission }\end{array}$ & 35 & 1361.17 & 2366.820 & 0.011 \\
\hline $\begin{array}{l}\text { Required ICU } \\
\text { admission }\end{array}$ & 37 & 5177.30 & 13013.151 & \\
\hline
\end{tabular}

diagnosed as having VTE, although only one of them was evaluated by imaging.

\section{DISCUSSION}

Patients with COVID-19 infection especially those with severe and critical infection remain at risk of VTE due to multiple factors including immobilisation, infection, respiratory failure, mechanical ventilation and central venous catheters. ${ }^{2}$ Abnormalities in coagulation including high D-dimers levels and procoagulant changes seem to be common and associated with poorer outcome. ${ }^{3}$ The frequency of VTE in our study was $11.2 \%$ (12 patients) with half of the patients developing pulmonary embolism. Four patients were diagnosed with VTE within 24 hours of admission, while the remaining eight patients developed VTE despite being on prophylactic anticoagulation. The rates of venous thromboembolism in patients with severe COVID-19 have been reported to range from $3.2 \%$ in non-ICU patients to $39 \%$ among ICU patients. ${ }^{3}$ A recent Dutch study found a $49 \%$ cumulative incidence of thrombotic complication among COVID-19 pneumonia patients in intensive care unit. ${ }^{5}$ Other studies have reported the incidence of thrombosis in around $20 \%-30 \%$ of the critically ill patients even with prophylaxis. ${ }^{4} 6$

In a study in Milan, Italy, thromboembolic events occurred at a cumulative rate of $21 \%(27.6 \%$ of ICU, $6.6 \%$ general ward patients) with half of the 
Table 4 Imaging results for VTE and corelation with D-dimers and anticoagulation protocol

\begin{tabular}{|c|c|c|c|c|c|}
\hline & & Imaging rest & s for VTE & & \\
\hline & & $\begin{array}{l}\text { No imaging } \\
\text { done }\end{array}$ & $\begin{array}{l}\text { VTE on } \\
\text { imaging }\end{array}$ & $\begin{array}{l}\text { No VTE on } \\
\text { imaging }\end{array}$ & Total \\
\hline VTE frequency according to & No anticoagulation & 3 & 0 & 0 & 3 \\
\hline anticoagulation protocol & Suboptimal prophylactic & 8 & 0 & 1 & 9 \\
\hline & Optimal prophylactic & 60 & 8 & 8 & 76 \\
\hline & Therapeutic dose & 0 & 4 & 1 & 5 \\
\hline & On regular DOACs/warfarin & 13 & 0 & 1 & 14 \\
\hline & Total & 84 & 12 & 11 & 107 \\
\hline VTE frequency based on D- & D-dimers $<2000$ & 40 & 2 & 9 & 51 \\
\hline dimers cut-off of >2000 & D-dimers $>2000$ & 14 & 7 & 0 & 21 \\
\hline & No D-dimers available & 30 & 3 & 2 & 35 \\
\hline & Total & 84 & 12 & 11 & 107 \\
\hline
\end{tabular}

DOACS, direct oral anticoagulants; ICU, intensive care unit; VTE, venous thromboembolism.

thromboembolic events diagnosed within 240.23 hours of hospital admission. ${ }^{7}$

Few researchers have reported a low incidence of VTE in COVID-19 pneumonia patients. Cattaneo et al $l^{8}$ reported no patient as having DVT in a study of non-ICU patients in Northern Italy. Other researchers have postulated that the incidence of VTE may have been overestimated in studies as immunothromboses associated with COVID-19 have been included as PE in these instances. ${ }^{9}$

However, VTE still remains a concern in patients with COVID-19 as the incidence of VTE in other viral pneumonia have been reported to be low. Bunce $e t a l^{10}$, for example, reported incidence of vascular thromboses of $5.9 \%$ in influenza $\mathrm{H} 1 \mathrm{~N} 1$.

The mean D-dimers in our study on first evaluation was high as expected (3322.24 ng/mL $\pm 9603 \mathrm{ng} /$ $\mathrm{mL}$ ) with one patient having D-dimers value in excess of $70000 \mathrm{ng} / \mathrm{mL}$. Patients with respiratory failure and those requiring ICU admission had a significantly higher mean values. Marked elevation of D-dimers has been a common finding in patients with COVID-19 requiring hospitalisation. Although high D-dimmers levels are non-specific, it has consistently been reported as a poor prognostic marker in patients with COVID-19. Several studies have shown association of higher D-dimer values with mortality, reporting a higher D-dimers value in nonsurvivors compared with survivors. ${ }^{11}$

In addition to being a marker of disease severity, higher D-dimer values have also been associated with high risk of VTE in patients with COVID-19 pneumonia as expected. ${ }^{12}$ Some authors have suggested anticoagulation therapy in patients with severe COVID-19 and higher D-dimers value over four times upper limit of normal. ${ }^{13}$ Others have suggested the need to adapt for anticoagulation in patients with COVID-19 as prophylactic anticoagulation does not avoid the occurrence of PE in these hospitalised patients. ${ }^{12}$ Importantly, significantly increased D-dimer is a good index for identifying high-risk groups of VTE. Cui et $a l^{14}$ suggested that a cut-off value of $1500 \mathrm{ng} / \mathrm{mL}$ has a sensitivity of $85.0 \%$, specificity $88.5 \%$ and the negative predictive value (NPV) of $94.7 \%$ for predicting VTE. In our study, all the patient with D-dimers value above 2000 $\mathrm{ng} / \mathrm{mL}$ had confirmed VTE on imaging. This underscores the importance of keeping a low threshold for evaluating patients with high D-dimers value with dedicated imaging for excluding VTE in the right clinical scenario. The study further informs the readers of the real-life NHS hospital evidence of coagulopathy in patients with COVID-19 patients and also helps in establishing a cutt-off value for D-dimers in these patients, which will help in establishing appropriate diagnostic algorithms for VTE in these cases and their subsequent management.

The study had several limitations being a small scale; single-centre study and the fact that not all of the patients involved in the study including those with high D-dimers were evaluated by dedicated imaging. In addition, as the study is retrospective in nature, many patients did not undergo complete laboratory investigations including D-dimers. Despite this, we have demonstrated that VTE is common in patients with COVID-19 infection with an incidence of approximately $11 \%$ even in optimally anticoagulated patients and that a D-dimer value above 2000 $\mathrm{ng} / \mathrm{mL}$ is correlated well with radiological confirmation of VTE. We have also demonstrated that significantly elevated D-dimer values are associated with the requirement for intensive care. Therefore, the authors recommend that a D-dimer needs to be done on admission for all patients with COVID-19 and a result of more than $2000 \mathrm{ng} / \mathrm{mL}$ should lead to a consideration of appropriate imaging to exclude VTE.

Further large-scale studies will help in understanding the true incidence and significance of VTE and the optimal investigation algorithms in these patients. 
approval of the version. BS and FR contributed to design of the work, data analysis, critical revision for important intellectual content and final approval of the version. All four authors agree to be accountable for all aspects of the work in relation to accuracy and integrity of the work.

Funding The authors have not declared a specific grant for this research from any funding agency in the public, commercial or not-for-profit sectors.

Competing interests None declared.

Patient and public involvement Patients and/or the public were not involved in the design, or conduct, or reporting, or dissemination plans of this research.

Patient consent for publication Not required.

Provenance and peer review Not commissioned; externally peer reviewed.

Data availability statement All data relevant to the study are included in the article or uploaded as supplementary information.

Open access This is an open access article distributed in accordance with the Creative Commons Attribution Non Commercial (CC BY-NC 4.0) license, which permits others to distribute, remix, adapt, build upon this work non-commercially, and license their derivative works on different terms, provided the original work is properly cited, appropriate credit is given, any changes made indicated, and the use is non-commercial. See: http://creativecommons.org/licenses/by-nc/4.0/.

ORCID iD

Muhammad Ziaullah Khan http://orcid.org/0000-0002-1530-3827

\section{REFERENCES}

1 Huang C, Wang Y, Li X, et al. Clinical features of patients infected with 2019 novel coronavirus in Wuhan, China. Lancet 2020;395:497-506.

2 Wang D, Hu B, Hu C, et al. Clinical characteristics of 138 hospitalized patients with 2019 novel coronavirus-infected pneumonia in Wuhan, China. JAMA 2020;323:1061-9.
3 Tang N, Li D, Wang X, et al. Abnormal coagulation parameters are associated with poor prognosis in patients with novel coronavirus pneumonia. J Thromb Haemost 2020;18:844-7.

4 Middeldorp S, Coppens M, van Haaps TF, et al. Incidence of venous thromboembolism in hospitalized patients with COVID-19. J Thromb Haemost 2020.

5 Klok FA, Kruip MJHA, van der Meer NJM, et al. Confirmation of the high cumulative incidence of thrombotic complications in critically ill ICU patients with COVID-19: an updated analysis. Thromb Res 2020;191:148-50.

6 Poissy Jet al. Pulmonary embolism in COVID-19 patients: awareness of an increased prevalence. Circulation 2020.

7 Lodigiani C, lapichino G, Carenzo L, et al. Venous and arterial thromboembolic complications in COVID-19 patients admitted to an academic hospital in Milan, Italy. Thromb Res 2020;191:9-14.

8 Cattaneo M, Bertinato EM, Birocchi S, et al. Pulmonary embolism or pulmonary thrombosis in COVID-19? is the recommendation to use high-dose heparin for thromboprophylaxis justified? Thromb Haemost 2020.

9 Desborough MJR, Doyle AJ. Image-proven thromboembolism in patients with severe COVID-19 in a tertiary critical care unit in the United Kingdom. Thromb Res 2020.

10 Bunce PE, High SM, Nadjafi M, et al. Pandemic H1N1 influenza infection and vascular thrombosis. Clin Infect Dis 2011;52:e14-17.

11 Zhou F, Yu T, Du R, et al. Clinical course and risk factors for mortality of adult inpatients with COVID-19 in Wuhan, China: a retrospective cohort study. Lancet 2020;395:1054-62.

12 Bompard F, Monnier H, Saab I, et al. Pulmonary embolism in patients with COVID-19 pneumonia. Eur Respir J 2020;56. doi:10.1183/13993003.01365-2020. [Epub ahead of print: $30 \mathrm{Jul}$ 2020].

13 Lin L, Lu L, Cao W, et al. Hypothesis for potential pathogenesis of SARS-CoV-2 infection-a review of immune changes in patients with viral pneumonia. Emerg Microbes Infect 2020;9:727-32.

14 Cui S, Chen S, Li X, et al. Prevalence of venous thromboembolism in patients with severe novel coronavirus pneumonia. $J$ Thromb Haemost 2020;18:1421-4. 